\title{
Noah's Ark on Mars
}

\author{
Xiao Man Luo ${ }^{1, \text { a }}$ \\ ${ }^{1}$ School of North China Electric Power University, Baoding 071000, China \\ a719481750@qq.com
}

\begin{abstract}
Mars is a planet of mystery and temptation that attracts many science fiction enthusiasts. Migration to Mars has been the topic of many fiction films for a long time. As the first successful Mars landing, this fiction seems to have the chance to realize.First step, we defined some parameters that connect to those three prior elements to calculate. Next we set some norms to judge whether the system could meet the requirement. Secondly, to fetch data we generated a sample population of 10,000 people to emigrate to Mars. To make the simulation more appropriate, the distribution of citizen in terms of factors were taken into consideration. In this model, we adapted the data from some provinces in China. Third, in this model we combined those three elements and judged this model to ensure the model could achieve the goal and determine the optimal minimum wage and salary distribution.Besides, we proposed the optimized model to compare the previous one so that the plan could be more perfect and practical.
\end{abstract}

Keywords: The grey model, the multiple linear regression prediction

\section{Introduction}

As the first successful Mars landing, this fiction seems to have the chance to realize. Worldwide, an enormous amount of research effort goes into Mars. With the goal of creating an optimal workforce to give all people the greatest quality of life with a vision of sustainability for the next 100 years. we divided the employments' group and ensure their considerations. According to this we detailed our models to optimize the system to obtain the best result. Next, taking some extra elements into consideration like other people's migration and some accidents happened which might entail much population movement. Therefore, we improved our model to make it still functional and discuss the strengths and weakness of it in some detail. In the end, we wrote a policy recommendation addressed to the director of LIFE that includes the factors of income, education, equality policies based on our model.

\section{Models}

\subsection{Define Parameters}

In this task we divided elements into two kinds, one is the prior elements and the other is other elements. After this we define parameters to apply them into calculation.

1. Prior Elements

- Income:

W: Minimum Wage Protection;

E: Engel coefficient.

These two parameters can reflect the quality of living for all citizens.

- Education:

Ed: The ratio of population having received higher education (including the proportion of doctor's degree, graduate degree and undergraduate degree) which is equal to the average of those ratios;

Eb: The basic education facilities containing rate.

- Equality:

$\mathrm{Pb}$ : The birth rate of labor population which is the reflection of the equality and can be used to measure the maternity, paternity leave and affordable childcare to ensure people can remain in the workforce; 
Wo: the rate of female employment;

Gini: the level of Gini coefficient.

2. Other Elements

- F: Features of the population contains the proportion of the aging population, gross population and population growth rate and death rate.

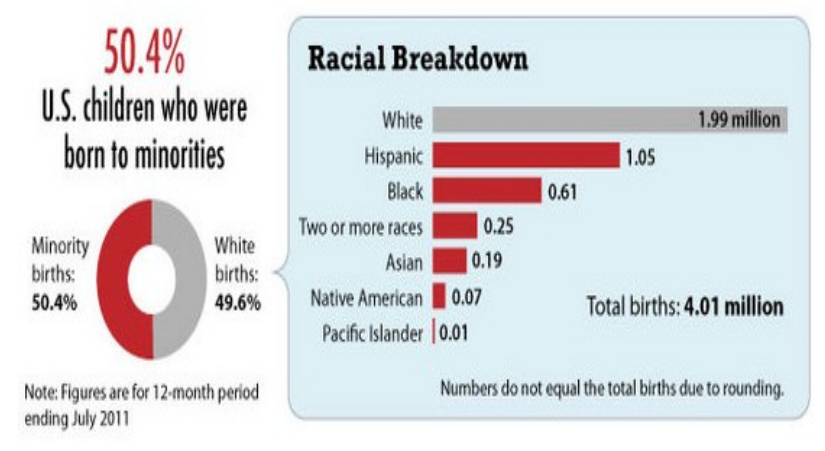

Figure 1 Different races’ impact on Demographic

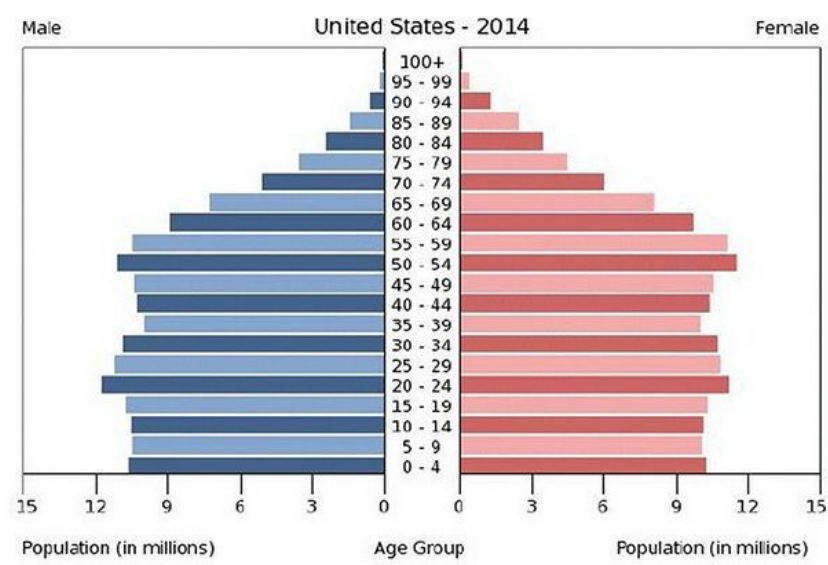

Figure 2 The Sex Ratio and Age Structure in U.S.A (2014)

3. The Ideal Index after Establishing the Model

- Income: the minimum wage guarantee will increase to $1.2 \mathrm{~W}$;

- Education: the ratio of population having received higher education can reach to 1.2Ed and the basic education facilities containing rate might be $0.8 \mathrm{Ed}$;

- Equality: the birth rate of labor population will decrease to $0.8 \mathrm{~Pb}$;

- Other elements: the female employment rate will reach to $1.2 \mathrm{Wo}$;

- Other elements: the level of Gini index will decrease to 0.8Gini.

With the help of MATLAB, we get the two figures below.

\subsection{Model for Task 2}

To get the data reflects the characters which meet the result of Task 1 , we generated a sample population of 10,000 people to emigrate to Mars. Extract data got from a census dataset. The characters and relevant factors are as follows: 
Table 1 The sample of 10,000 people

\begin{tabular}{cccccccc}
\hline Gender & \multicolumn{3}{c}{ Age } & \multicolumn{3}{c}{ Education } \\
Men & Women & Teenager & Youth & $\begin{array}{c}\text { Mid-age } \\
\text { and the } \\
\text { old }\end{array}$ & $\begin{array}{c}\text { High } \\
\text { school } \\
\text { graduates }\end{array}$ & $\begin{array}{c}\text { Under- } \\
\text { graduate }\end{array}$ & $\begin{array}{c}\text { Master } \\
\text { and } \\
\text { doctors' } \\
\text { graduates }\end{array}$ \\
\hline $\begin{array}{c}\text { Family } \\
\text { Structure }\end{array}$ & 4874 & 3839 & 3579 & 2582 & $\begin{array}{c}2105 \\
\text { Years of } \\
\text { service }\end{array}$ & 4015 & 1977 \\
Married & Single & Scientist & Worker & Student & $\begin{array}{c}\text { one to five } \\
\text { years }\end{array}$ & $\begin{array}{c}5 \text { to } 10 \\
\text { years }\end{array}$ & $\begin{array}{c}15 \text { to } 30 \\
\text { years }\end{array}$ \\
\hline 3800 & 5321 & 53 & 5389 & 3000 & 3274 & 2500 & 1678 \\
\hline
\end{tabular}

To build a peaceful, cooperative, egalitarian society, we build this sample which can develop the strategy further. For example, we obtain the equitable distribution of innovators versus producers from the statistics of social identity; the skilled versus unskilled labor from the years of service and education; the families versus single people from family structure.

1. Consider the birth rate

Thus, according to the statistics, we obtain that the best birth rate is between $7 \%$ and $12 \%$ according to the statistics. And we chose two towns whose population is about 10,000 to simulate and calculate when their birth rate will go beyond the range.

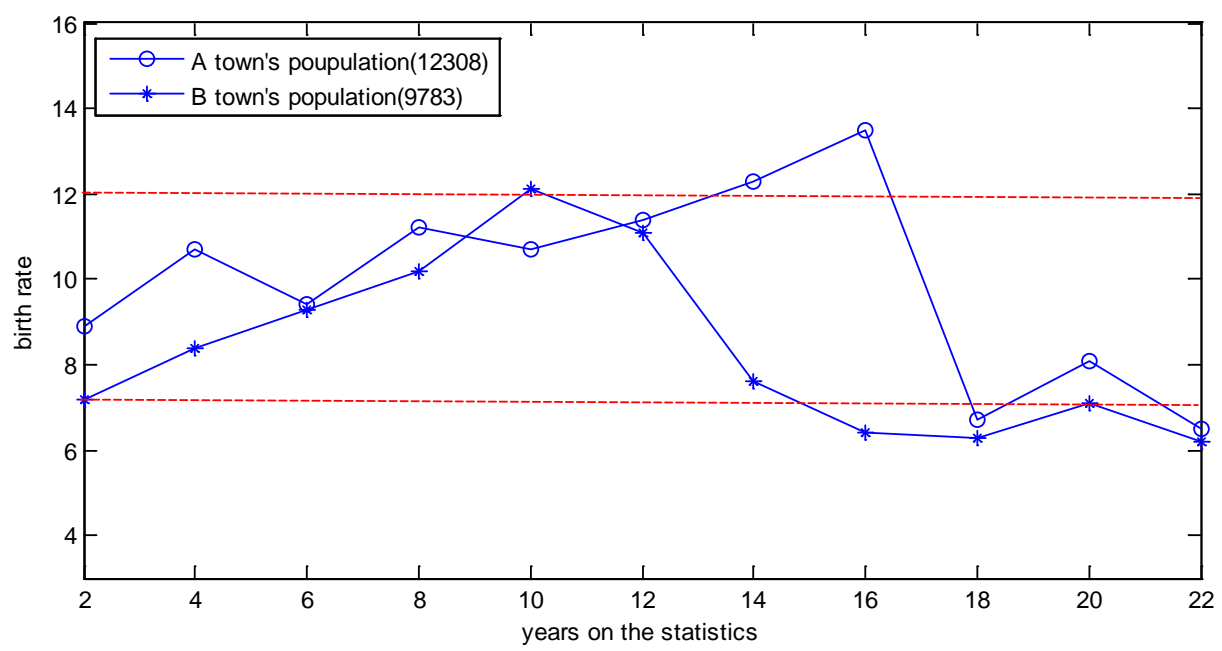

Figure 3 Two Town's Population's Simulation (the birth rate)

The figure shows large fluctuation of spinning force occurs after 12 or 14 years ago.

2. Considering the Ratio of Sex

On the basis of the statistics, we find that the best gender ratio in the 10,000 people sample is between $47 \%$ and $54 \%$. The same with the method above, the original data are as sample used to simulate the gender rate will go beyond the range. 


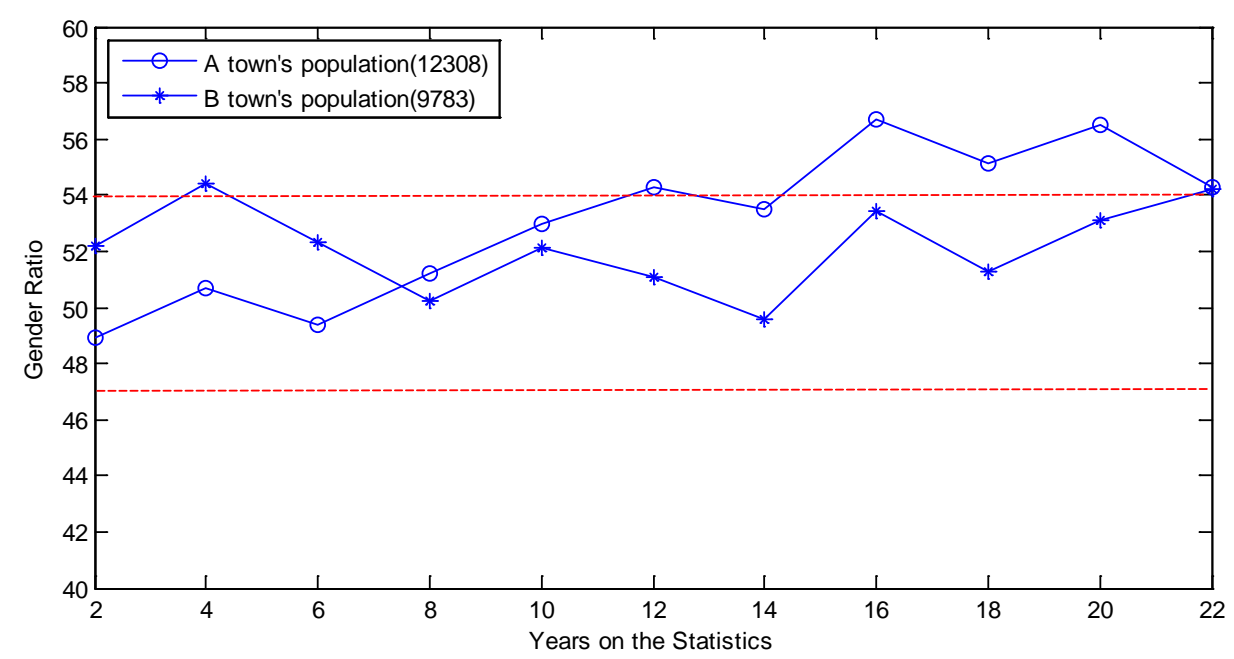

Figure 4 Two Town's Population's Simulation (the ratio of sex)

The graph shows that the gender goes beyond the critical line after 11 or 13 years.

Synthesize the two factors, and we obtain that in order to ensure the goals of UTOPIA 2100 continue to be met, we should assess the model about 12 years later and take proper measures to adjust it.

\section{Conclusions}

We choose ten factors that have influence on the country's comprehensive strength, which makes the description of the comprehensive strength more or less incomplete.

Using the grey model and combined it with the multiple linear prediction which can help us get the multiple linear regression equation between factors and dependent variable.

In this model we combined those three elements and judged this model to ensure the model could achieve the goal and determine the optimal minimum wage and salary distribution.Besides, we proposed the optimized model to compare the previous one so that the plan could be more perfect and practical.

\section{References}

[1] Using machine learning to predict the results of sporting matches. BAULCH M. . 2001

[2] Predicting Olympic Medal Counts:The effects of eco-nomic development on olympic performance. Bian Xun. Park Place Eco . 2005

[3] Lee E S. A theory of migration[J]. Demography, 1966,3(1):47-57.

[4] Lewis W A. Economic development with unlimited supplies of labor [J]. The Manchester School of Economic and Social Studies, 1954, 22(2):139-191.

[5] Liisa H. Malkki, Refugees and Exile: From "Refugee Studies" to the National Order of Things, Annual Review of Anthropology, 1995, 24: 495-523.

[6] Eric Neumayer, Bogus Refugees? The Determinants of Asylum Migration to Western Europe , International Studies Quarterly, 2005, 49(3):389-410.

[7] Roger Zetter, More Labels, Fewer Refugees: Remaking the Refugee Label in an Era of

Globalization, Journal of Refugee Studies, 2007, 20(2):172-192.

[8] Eleonore Kofman, Gender and International Migration in Europe: Employment, Welfare, and Politics, 2000 